\title{
Expansion Velocity Model of Steam-Assisted Gravity Drainage considering Thermal Convection
}

\author{
Dian-Fa Du, ${ }^{1}$ Yao-Zu Zhang $\mathbb{D}^{1}{ }^{1}$ Li-Na Zhang, ${ }^{2}$ Meng-Ran Xu, ${ }^{1}$ and Xin Liu ${ }^{2}$ \\ ${ }^{1}$ College of Petroleum Engineering, China University of Petroleum, Qingdao, China \\ ${ }^{2}$ Research Institute of Petroleum Exploration \& Development, East China Company, SINOPEC, Nanjing, China \\ Correspondence should be addressed to Yao-Zu Zhang; 2650527785@qq.com
}

Received 9 March 2021; Revised 27 May 2021; Accepted 5 June 2021; Published 22 June 2021

Academic Editor: Chenhao Sun

Copyright (C) 2021 Dian-Fa Du et al. This is an open access article distributed under the Creative Commons Attribution License, which permits unrestricted use, distribution, and reproduction in any medium, provided the original work is properly cited.

\begin{abstract}
Steam-assisted gravity drainage (SAGD) is an important method used in the development of heavy oil. A heat transfer model in the SAGD production process is established based on the heat transfer effect caused by the temperature difference at the front edge of the steam chamber and the heat convection effect caused by the pressure difference. The observation well temperature method is used in this model to calculate the horizontal expansion speed of the steam chamber. In this manner, an expansion speed model considering heat convection and heat conduction is established for a steam chamber with a steam-assisted gravity drainage system. By comparing this with the production data extracted from the Fengcheng Oilfield target block, it is verified that the model can be effectively applied for actual field development. Simultaneously, by using the derived model, the temperature distribution at the edge of the steam chamber and production forecast can be predicted. Sensitivity analysis of the expansion rate of the steam chamber demonstrates that the larger the thermal conductivity, the faster is the steam chamber horizontal expansion speed, and the two are positively correlated; the larger the reservoir heat capacity, the slower is the steam chamber horizontal expansion speed. A larger heat capacity of the convective liquid indicates that there are more water components in the convective liquid, the viscosity of the convective liquid is low, and the expansion speed of the steam chamber increases accordingly. This research closely integrates theory with actual field production and provides theoretical support for the development of heavy oil reservoirs.
\end{abstract}

\section{Introduction}

Steam-assisted gravity drainage (SAGD) is one of the most important methods currently used for the development of heavy oil. It is characterised by a high recovery rate, a high degree of steam cavity formation, and it takes effect quickly and has a low pollution rate. For SAGD production, the degree to which the steam chamber is developed directly determines the developmental effect of the steam-assisted gravity drainage system as well as the efficiency of the oil displacement and its recovery factor. The steam, which is at a high temperature, heats the oil sands and heavy oil, which are at a low temperature, and the viscosity of the liquid then rapidly drops to form a cavity. The production mechanism is illustrated in Figure 1. Gravity pulls the condensate and heavy oil down from the drain zone to the edge, and down to the production well, while the heat exchange is predominantly produced by heat conduction and convection at the edge of the steam cavity. The heat transfer and expansion speed models of the steam chamber are the key factors determining the degree of steam cavity development. Therefore, studying the heat transfer and velocity models in the SAGD oil recovery process is the primary task, and it is an extremely important step in evaluating the developmental effects and guiding actual production.

In the 1980 s, Butler $[1,2]$ analysed salt water injection well technology and applied it to the development of the heavy oil industry. When the steam cavity in a homogeneous oil reservoir only underwent heat conduction, he considered the establishment of a heat transfer model and a macroscopic gravity drainage heat transfer mathematical model. This oil drainage equation sets a precedent for the theoretical production of SAGD.

In the following years, Reis, Edmuds, Aukhaev, Azad, and others continued to improve upon this basic model, but they have not yet considered the influence of steam cavity thermal 

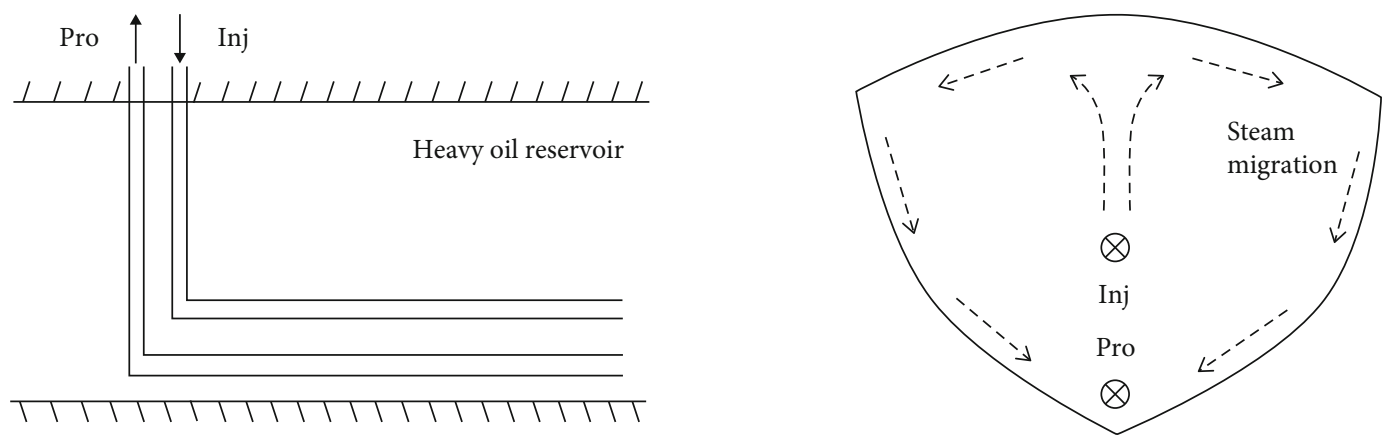

FIGURE 1: SAGD production mechanism diagram for double horizontal wells.

convection [3]. Sharma and Gates [4] assumed that the condensate velocity normal to the interface was the steam chamber interface velocity multiplied by the fluid mobility ratio. Although it is an assumption, the resultant equation provides an understanding of the role of convection. In 2013, Irani and Ghannadi [5] conducted a certain degree of research on the convection caused by the water phase, and they established a steam-assisted gravity drainage heat transfer model that considered thermal convection. Irani believed in the heat transfer method of thermal convection, but their research on thermal convection was only carried out under ideal conditions, while actual reservoir conditions are far from ideal and can, of course, deviate considerably. Qing and Zhang [6] used a constant heat flow boundary condition to verify the widely used constant-temperature boundary condition at the edge of the steam chamber. Our study confirmed the accuracy of the study by Irani et al. He offered a simple formula to demonstrate the connection between the condensate velocities normal to the chamber interface and the movement velocity of the chamber interface, which is helpful for studying the expansion speed of the steam cavity and heat convection. Yang et al. [7] and Fan and Li [8] also proposed that heat conduction and heat convection exist simultaneously during SAGD production. Furthermore, they believe that heat convection, when in the vicinity of the steam cavity, is the main mechanism by which heat is transferred. This study confirmed that thermal convection occurs during SAGD production. It also considered the heterogeneity of the reservoir and established a relatively complete heat transfer model. However, the study argues that thermal convection is only generated by the water phase and that the steam cavity expansion rate is a fixed value. Therefore, the research results deviate from the actual reservoir conditions.

Professor Gates et al. [9] studied the influence of steam quality on $\Delta R$ a temperature; if the steam quality was equal to $50 \%$, the supplied temperature exceeded $178.31^{\circ} \mathrm{C}$, which is unstable. The steam quality should be as high as possible at the edge of the chamber to enhance the instability for achieving maximum bitumen production from the reservoir. Given that the chamber is under saturation conditions, its temperature is constant; however, there exists a quality gradient throughout the chamber that is the highest at the injection well and decreases moving away from the injection well. In 2015, Gotawala and Gates [10] used linear stability analysis to check the stability of the edge of the steam cham- ber, as it will exist in the steam-assisted gravity drainage process. He observed that the densities and viscosities of the steam/water and bitumen are strong functions of temperature, and thus the energy content contributes to the stability criterion. If the difference in the energy-weighted DarcyRayleigh numbers of the steam/water phases and oil phase is negative, then the system is unstable and perturbations of the edge grow. We herein observe that the higher the steam quality and steam injection temperature, the greater is the instability of the edge of the chamber, which is more conducive to the horizontal expansion of the steam chamber.

The convection phase during the actual production process comprised a mixed phase of condensed water and crude oil. Taking this into consideration, Liu et al. [11] discovered a heat conduction effect caused by the temperature difference at the front edge of the steam chamber, as well as a convection effect caused by the pressure difference. This steam chamber heat transfer model is more in line with the actual conditions. Although it improves upon the heat transfer model used in the SAGD production process by making it more complete, it only idealises the steam chamber expansion speed parameter as a fixed value and has not yet offered a suitable calculation method. Therefore, when the expansion speed of the steam chamber changes, the results deviate.

Based on Butler's basic heat transfer model, Zhou et al. [12] proposed the theory that the expansion speed of the steam chamber is variable. The steam chamber expansion speed was obtained through both the observation well temperature method and the drain zone temperature distribution method. The newly changed steam chamber expansion speed in this study takes into account the influencing factors when the steam cavity expands but again idealises the reservoir conditions while ignoring the heat convection phenomenon caused by the pressure difference. This steam cavity expansion model is based only on the heat transfer that considers heat conduction. However, during the actual production process, thermal convection is the main mechanism by which steam transfers heat at the drain zone, and it is also a key factor affecting the expansion speed of the steam chamber. Therefore, the results show a large deviation from the actual production situation.

In 2020, Zargar et al. [13] established a comprehensive constant heat injection (CCHI) model by studying the relation between steam injection parameters and oil production. This model considers the expansion speed of the steam 
chamber as the production time increases; it decreases owing to the relation between energy and mass balances. Zargar's study has considered that the steam chamber expansion rate is a variable during the SAGD production process, and it has thus calculated it using the CCHI model to obtain the best steam injection parameters. However, this study only confirmed that the expansion speed of the steam chamber was variable, and the horizontal expansion speed of the steam chamber could not be obtained through the CCHI model. There is no explanation for the influence of the changing steam chamber expansion rate on the steam chamber expansion law. Simultaneously, the changing steam chamber expansion speed has not been studied, and the steam chamber horizontal expansion speed model has not been obtained, so predicting the steam chamber migration law is impossible. There is an urgent need for a complete and accurate steam chamber expansion speed model for SAGD production.

Therefore, in this study, considering that the convective liquid is composed of a mixed phase of condensate and crude oil, introducing the thermal convection velocity which includes the relative permeability, viscosity, pressure, and other parameters of the two phases, the thermal convection velocity is considered in the SAGD steam cavity heat transfer model. In addition, as the steam cavity's heat transfer model considers both heat conduction and heat convection, the observation well temperature method is used to establish the expansion velocity model of the steam cavity. This is used to calculate the horizontal expansion velocity of the drain zone and predict the temperature distribution in both the drain zone and in SAGD production. We herein provide a tool for rapid field-scale optimisation and performance predictions, as opposed to the use of extremely timeconsuming thermal numerical simulators.

\section{Steam Chamber Expansion Research}

2.1. Model Assumptions. The entire production process for steam-assisted gravity drainage can be divided into three main stages-the rising stage of the steam chamber, lateral expansion stage, and decay stage [14-16]. The production characteristics of each stage are different. The key stage for oil production is the horizontal expansion stage of the steam chamber. This stage comprises the peak oil drainage period during SAGD production, and it is the core stage required to study the expansion speed of the steam chamber.

However, we herein selected the steam cavity's lateral expansion stage as the research target. To facilitate our research, the following assumptions were made for when the steam cavity moved laterally along the top of the reservoir:

(1) The oil reservoir is a homogeneous reservoir

(2) The steam chamber reached the top of the reservoir and began to expand laterally on both sides

(3) The thermal conductivity of the reservoir was constant
(4) Both heat conduction and convection occur in the reservoir

(5) Heat transfer only moves in a direction perpendicular to the outer edge of the steam chamber; that is, there is a one-dimensional heat transfer process

(6) At a certain moment, the system is in a quasisteady state process; that is, at a certain moment, the steam chamber advances at a fixed speed along the edge in a normal direction

(7) We ignored the heat loss during the flow of heavy oil

2.2. Heat Transfer Model. According to Butler's research [1, $2]$, the heat transfer process at the front interface of steamassisted gravity drainage of the steam cavity is a pseudosteady-state process. Figure 2 is a schematic of the expansion of the steam chamber, and it shows that the basic heat transfer differential equation can be obtained according to the conservation of energy:

$$
K \nabla^{2} T-\rho_{c} c_{p c}(\nu \cdot \nabla T)=\rho_{\mathrm{r}} c_{p r} \dot{T} .
$$

The first term on the left side of the equation represents the heat conduction of the steam chamber, and the second term on the left side represents the heat convection that runs perpendicular to the direction of the steam chamber:

$$
\begin{aligned}
& K\left(\frac{\partial^{2} T}{\partial x^{2}}+\frac{\partial^{2} T}{\partial y^{2}}+\frac{\partial^{2} T}{\partial z^{2}}\right)-\rho_{c} c_{p c}\left(V \frac{\partial T}{\partial x}+V \frac{\partial T}{\partial y}+V \frac{\partial T}{\partial z}\right) \\
& \quad=\rho_{r} c_{p r}\left(\frac{\partial T}{\partial t}\right),
\end{aligned}
$$

where $K$ is the reservoir thermal conductivity, $V$ is the convective velocity, $\rho_{c}$ is the convective phase density, $\rho_{r}$ is the reservoir density, $c_{p c}$ is the specific heat capacity of the convective liquid, $c_{p r}$ is the specific heat capacity of the reservoir, $x$ is the normal direction of the steam cavity interface, $y$ is the tangent direction of the steam chamber interface, and $z$ is parallel to the horizontal well axis.

As the oil reservoir is a homogeneous reservoir, the temperature gradient in the $x$ and $y$ directions can be ignored, and Equation (2) can be converted as follows:

$$
K\left(\frac{\partial^{2} T}{\partial x^{2}}\right)-\rho_{c} c_{p c}\left(V \frac{\partial T}{\partial x}\right)=\rho_{\mathrm{r}} c_{p r}\left(\frac{\partial T}{\partial t}\right) .
$$

Introducing the variable $\xi$ (apparent distance) [17], we deduce according to the assumptions that the expansion speed $U_{\zeta}$ of the steam chamber for a certain period of time is a fixed value.

$$
\xi=x-\int_{0}^{t} U_{\xi} d t=x-U_{\xi} t .
$$




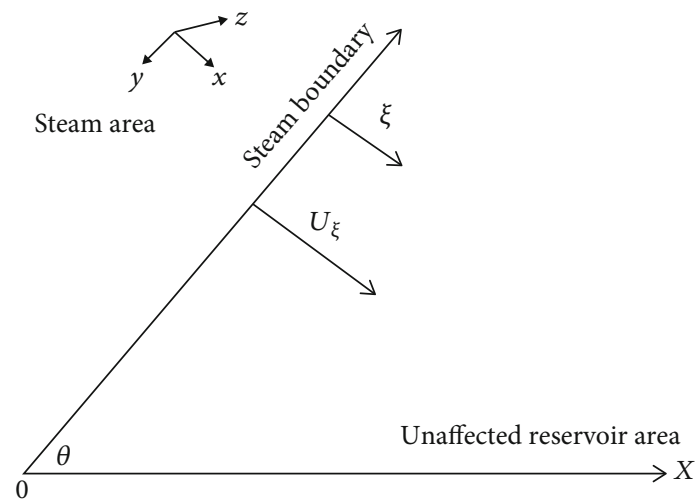

Figure 2: Steam chamber expansion diagram.

In the equation, the partial differential of $x$ is replaced by $\xi$ :

$$
\begin{aligned}
& \frac{\partial^{2} T}{\partial x^{2}}=\frac{\partial^{2} T}{\partial \xi^{2}}, \\
& \frac{\partial T}{\partial t}=-U_{\xi} \frac{\partial T}{\partial \xi} .
\end{aligned}
$$

Substituting Equations (5) and (6) into Equation (3), we obtain

$$
K\left(\frac{\partial^{2} T}{\partial \xi^{2}}\right)-\left(\rho_{c} c_{p c} V-\rho_{r} c_{p r} U_{\xi}\right)\left(\frac{\partial T}{\partial \xi}\right)=\rho_{r} c_{p r}\left(\frac{\partial T}{\partial t}\right) .
$$

When the heat transfer at the front edge of the steam chamber is stable, and the temperature distribution does not change with time, Equation (7) becomes Equation (8).

$$
K\left(\frac{\partial^{2} T}{\partial \xi^{2}}\right)-\left(\rho_{c} c_{p c} V-\rho_{r} c_{p r} U_{\xi}\right)\left(\frac{\partial T}{\partial \xi}\right)=0 .
$$

The above equation is the SAGD heat transfer model that considers both heat conduction and heat convection.

2.3. Temperature Distribution at the Edge of Steam Chamber. Based on the SAGD heat transfer model, with the following boundary conditions:

$$
\left\{\begin{array}{l}
T(\infty)=T_{r}, \\
T(0)=T_{s}
\end{array}\right.
$$

We can obtain

$$
\begin{aligned}
& T=T_{r}+\left(T_{s}-T_{r}\right) \times e^{\rho_{c} c_{p c} V-\rho_{r} c_{p r} U_{\xi} / K \times \xi}, \\
& \xi=\frac{K}{U_{\xi} \rho_{r} c_{p r}-V \rho_{c} c_{p c}} \ln \frac{T_{\mathrm{s}}-T_{\mathrm{r}}}{T-T_{\mathrm{r}}} .
\end{aligned}
$$

The viscosity distribution in crude oil is an important factor in determining temperature distribution. As the viscosity distribution in crude oil has a certain power function relation with temperature [18], the relation between the two can be approximately expressed as

$$
\frac{\mu_{s}}{\mu_{o}}=\left(\frac{T-T_{r}}{T_{s}-T_{r}}\right)^{m}
$$

where $\mu_{s}$ is the oil viscosity when at the injected steam temperature, $\mu_{o}$ is the oil viscosity, $T$ is the temperature at a certain point on the edge of the steam chamber, $T_{r}$ is the original reservoir temperature, $T_{s}$ is the temperature of the injected steam, and $m$ denotes the temperature-viscosity factor.

Irani and Ghannadi studied the convection caused by the water phase in the SAGD process and observed that the pressure distribution at the front edge of the steam chamber is also in the form of a power function. Figure 3 was obtained through the calculation of Irani's model. According to the comparison, the temperature and pressure distribution trends at the front edge of the steam chamber were similar. Therefore, according to Equation (11), the pressure distribution at the edge of the steam chamber is in a power function relation with the viscosity distribution of crude oil [11]:

$$
\frac{\mu_{s}}{\mu_{o}}=\left(\frac{P-P_{r}}{P_{s}-P_{r}}\right)^{n},
$$

where $P$ is the pressure at a certain point on the edge of the steam chamber, $P_{r}$ is the original reservoir pressure, $P_{s}$ is the injection pressure, and $n$ is the pressure-viscosity factor.

By combining the above two equations, the relation between the temperature and pressure distributions can be obtained.

$$
\frac{P-P_{r}}{P_{s}-P_{r}}=\left(\frac{T-T_{r}}{T_{s}-T_{r}}\right)^{m / n}
$$

According to Equation (13), the derivative of $\xi$ can be obtained:

$$
\frac{1}{P_{s}-P_{r}} \frac{\partial P}{\partial \xi}=\frac{1}{\left(T_{s}-T_{r}\right)^{m / n}} \frac{m}{n}\left(T-T_{r}\right)^{m / n-1} \frac{\partial T}{\partial \xi},
$$

because the thermal convection velocity in the steam cavity is

$$
V=-\left(\frac{k k_{r o}}{\mu_{o}}+\frac{k k_{r w}}{\mu_{w}}\right) \frac{\partial P}{\partial \xi} .
$$

According to Sharma and Gate's research [4], the relative permeability of the oil and water phases is as follows:

$$
\left\{\begin{array}{l}
\frac{k k_{r o}}{\mu_{o}}=\frac{k k_{r o c w}}{\mu_{s}}\left(S_{\mathrm{oD}}\right)^{a}\left(1-T^{*}\right)^{a}\left(T^{*}\right)^{m} \\
\frac{k k_{r w}}{\mu_{w}}=\frac{k k_{r w r o}}{\mu_{w}}\left[1-S_{\mathrm{oD}}\left(1-T^{*}\right)\right]^{b}
\end{array}\right.
$$

where $k_{r o}$ is the relative permeability of the oil phase, $k_{r o c w}$ is the relative permeability of the oil phase when under an irreducible water saturation, $k_{r w}$ is the relative permeability of 


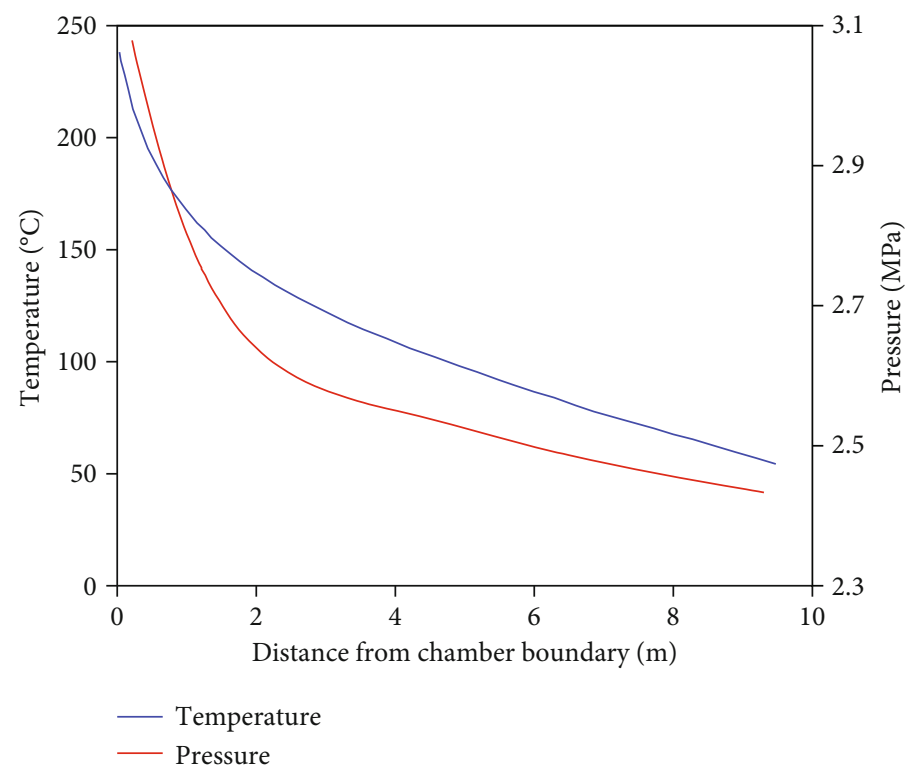

FIGURE 3: Temperature distribution and pressure distribution calculated from Irani and Ghannadi's model.

the water phase, $k_{\text {rwro }}$ is the relative permeability of the water phase under the residual oil saturation, $a b$ is the Corey coefficient, and $\alpha$ is the thermal diffusivity.

where $S_{\mathrm{oD}}=S_{i o}-S_{\mathrm{or}} / 1-S_{w c}-S_{\mathrm{or}}, T^{*}=T-T_{r} / T_{s}-T_{r}$ $=e^{-U_{\xi} \xi / \alpha}$.

Then, the fluidity of the edge of the steam chamber is

$\lambda=\frac{k k_{\text {rocw }}}{\mu_{s}}\left(S_{\mathrm{oD}}\right)^{a}\left(1-T^{*}\right)^{a}\left(T^{*}\right)^{m}+\frac{k k_{r w r o}}{\mu_{w}}\left[1-S_{\mathrm{oD}}\left(1-T^{*}\right)\right]^{b}$.

Substituting Equations (14) and (17) into Equation (15), we can obtain

$$
V=\frac{m U_{\xi} \lambda\left(P_{s}-P_{r}\right)}{n \alpha}\left(T^{*}\right)^{m / n}
$$

The above equation shows that the convection velocity is a function of $\xi$. When the thermal convection velocity is introduced into the edge temperature distribution function of the steam cavity, the edge temperature distribution function of the steam cavity can be considered for both heat conduction and thermal convection:

$$
\xi=\frac{n \alpha K}{n \alpha \rho_{r} c_{p r}-\rho_{c} c_{p c}\left[m \lambda\left(P_{s}-P_{r}\right)\left(T^{*}\right)^{m / n}\right]} \frac{1}{U_{\xi}} \ln \frac{T_{s}-T_{r}}{T-T_{r}} .
$$

2.4. Steam Chamber Expansion Speed Model. To better describe the development and expansion of the steam cavity during the SAGD production process, we herein use the observation well temperature measurement method to obtain the expansion speed of the steam cavity under the conditions of the known observation well position, steam cavity temperature, and oil reservoir temperature. This is car- ried out to further obtain the horizontal movement speed of the steam outlet cavity and its edge position, thereby providing a theoretical basis for field development.

In the same monitoring well, the temperature at two different depths in the high-temperature section can be measured separately, as shown in Figure 4.

The relation between the distance from the oil drain interface and the temperature at these two depths, when measured simultaneously, is as follows [12].

$$
\left\{\begin{array}{l}
\xi_{1}=\frac{K}{U_{\xi} \rho_{r} c_{p r}-V_{1} \rho_{c} c_{p c}} \ln \frac{T_{s}-T_{r}}{T_{1}-T_{r}}, \\
\xi_{2}=\frac{K}{U_{\xi} \rho_{r} c_{p r}-V_{2} \rho_{c} c_{p c}} \ln \frac{T_{s}-T_{r}}{T_{2}-T_{r}},
\end{array}\right.
$$

where $V_{1}$ is the convective velocity at observation point $1, V_{2}$ is the convective velocity at observation point $2, T_{1}$ is the temperature at observation point 1 , and $T_{2}$ is the temperature at observation point 2 .

$\xi$ can also be expressed as a function describing depth:

$$
\left\{\begin{array}{l}
\xi_{1}=\left(h_{1}-h_{\mathrm{o}}\right) \cos \theta \\
\xi_{2}=\left(h_{2}-h_{\mathrm{o}}\right) \cos \theta
\end{array}\right.
$$

$\xi_{2}$ minus $\xi_{1}$, and simplified to

$$
\begin{gathered}
\left(h_{2}-h_{1}\right) \cos \theta \frac{n \alpha K}{\rho_{r} c_{p r} n \alpha-\rho_{c} c_{p c}\left(T_{1}-T_{r} / T_{s}-T_{r}\right)} \frac{1}{U_{\xi}} \ln \frac{T_{1}-T_{\mathrm{r}}}{T_{2}-T_{\mathrm{r}}} \\
-\left[\frac{n \alpha K}{\rho_{r} c_{p r} n \alpha-\rho_{c} c_{p c}\left(T_{2}-T_{r} / T_{s}-T_{r}\right)}\right. \\
\left.-\frac{n \alpha K}{\rho_{r} c_{p r} n \alpha-\rho_{c} c_{p c}\left(T_{1}-T_{r} / T_{s}-T_{r}\right)}\right] \frac{1}{U_{\xi}} \ln \frac{T_{2}-T_{\mathrm{r}}}{T_{s}-T_{\mathrm{r}}} .
\end{gathered}
$$




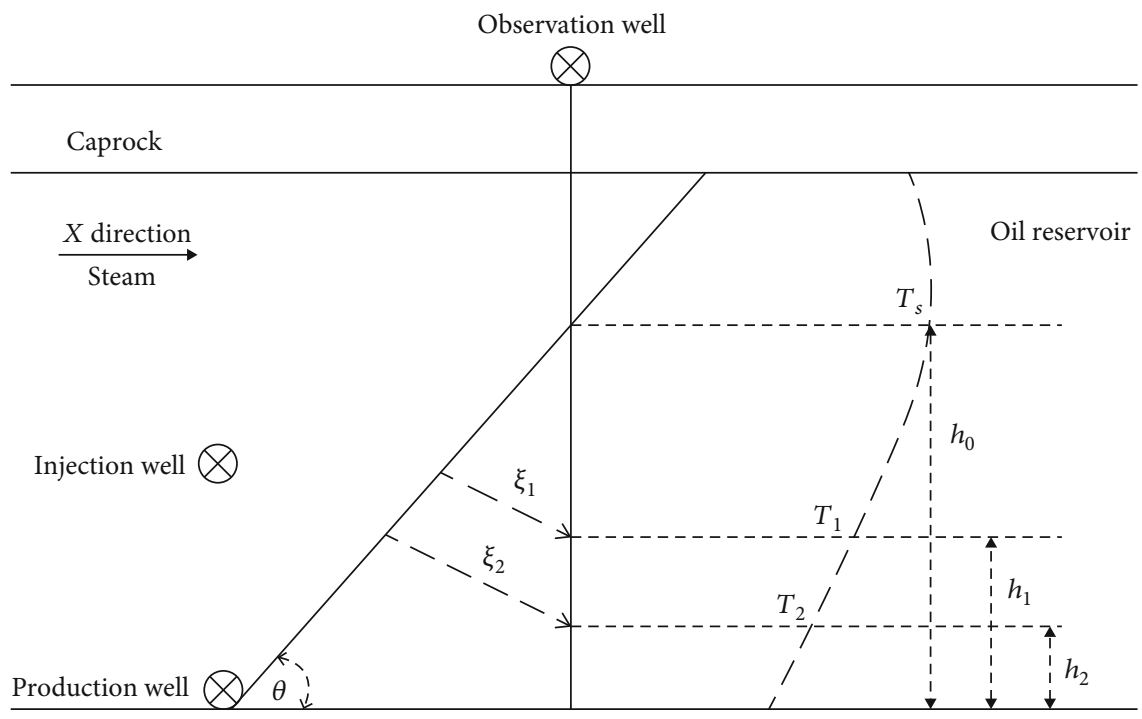

FIgURE 4: Schematic of the observation well temperature measurement method.

We can obtain

$$
\begin{aligned}
U_{\xi}= & \frac{n \alpha K}{\left(h_{2}-h_{1}\right) \cos \theta\left\{n \alpha \rho_{r} c_{p r}-\rho_{c} c_{p c}\left[m \lambda\left(P_{s t}-P_{r}\right)\right] \times\left(T_{1}-T_{\mathrm{r}} / T_{s}-T_{\mathrm{r}}\right)^{m / n}\right\}} \ln \\
& \cdot \frac{T_{1}-T_{r}}{T_{2}-T_{r}}+\left[\frac{n \alpha K}{\rho_{r} c_{p r} n \alpha-\rho_{c} c_{p c}\left(T_{2}-T_{r} / T_{s}-T_{r}\right)}\right. \\
& \left.-\frac{n \alpha K}{\rho_{r} c_{p r} n \alpha-\rho_{c} c_{p c}\left(T_{1}-T_{r} / T_{s}-T_{r}\right)}\right] \frac{1}{\left(h_{2}-h_{1}\right) \cos \theta} \ln \frac{T_{2}-T_{\mathrm{r}}}{T s-T_{\mathrm{r}}} .
\end{aligned}
$$

After simplification, the expansion velocity equation of the steam cavity interface, considering heat conduction and heat convection, is obtained as

$$
U_{\xi}=\frac{\varphi}{\left(h_{2}-h_{1}\right) \cos \theta} \ln \frac{T_{1}-T_{r}}{T_{2}-T_{r}}+\frac{\gamma}{\left(h_{2}-h_{1}\right) \cos \theta} \ln \frac{T_{1}-T_{r}}{T_{s}-T_{r}},
$$

where $\varphi=n \alpha K / n \alpha \rho_{r} c_{p r}-\rho_{c} c_{p c}\left[m \lambda\left(P_{s t}-P_{r}\right)\right] \times\left(T_{1}-T_{r} / T_{s}\right.$ $\left.-T_{r}\right)^{m / n}, \quad \gamma=n \alpha K / \rho_{r} c_{p r} n \alpha-\rho_{c} c_{p c}\left(T_{2}-T_{r} / T_{s}-T_{r}\right)-n \alpha K /$ $\rho_{r} c_{p r} n \alpha-\rho_{c} c_{p c}\left(T_{1}-T_{r} / T_{s}-T_{r}\right)$.

The horizontal expansion speed of the steam chamber is

$$
\begin{aligned}
U_{X}= & \frac{U_{\xi}}{\sin \theta}=\frac{2 \varphi}{\left(h_{2}-h_{1}\right) \sin 2 \theta} \ln \frac{T_{1}-T_{r}}{T_{2}-T_{r}} \\
& +\frac{2 \gamma}{\left(h_{2}-h_{1}\right) \sin 2 \theta} \ln \frac{T_{1}-T_{r}}{T_{s}-T_{r}} .
\end{aligned}
$$

Under the condition that the position and temperature of the oil layer are measured, according to Equation (25), the horizontal expansion speed of the steam chamber at the corresponding time can be obtained.

\section{Model Validation}

The model can be solved using a mathematical iterative method. To verify the accuracy of the desired steam chamber expansion speed model, Irani's model was compared with the new model, and the temperature change curves of the steam chamber at different depths of the two models were calculated by using MATLAB software; the parameters are listed in Table 1. In addition, the two models were compared with the production monitoring data of Well $\mathrm{Z}$ in the SAGD production test area of Xinjiang Fengcheng Oilfield. In the actual field, to observe the development and expansion of the steam cavity during the SAGD production process, an observation well was set between two horizontal wells. In addition, in the early stages of SAGD production, steam stimulation is usually required to ensure better development of the steam chamber. Therefore, the horizontal expansion stages of the steam chamber in the first and second years were excluded, so the third year of SAGD production was selected as the target year for our comparison.

Figure 5 shows the temperature change curves from the observation wells at different production times. Whether it is looking at the new model, the Irani and Ghannadi model, or the data from the actual field, you can see an obvious steam cavity development shape, and you can also see a temperature peak zone in the middle of the steam chamber [19-22]. Furthermore, the peak area was approximately 50 $\mathrm{m}$. As the depth of the steam chamber increased, the temperature gradually decreased from $220^{\circ} \mathrm{C}$ to $70^{\circ} \mathrm{C}$. The temperature curve of the entire steam chamber remains at $150^{\circ} \mathrm{C}-230^{\circ} \mathrm{C}$, which agrees well with previous research. As the thermal convection considered by the Irani and Ghannadi models is only a simplified case under ideal conditions and they have not yet considered the change in the expansion speed of the steam chamber, they are too idealistic compared to the new model derived in this study, so the peak temperature of the steam chamber and the steam chamber temperature at the same depth are much higher than those 
TABLE 1: Model verification parameter table.

\begin{tabular}{lccc}
\hline Item & Value & Item & Value \\
\hline Porosity & 0.3 & Steam temperature & $240^{\circ} \mathrm{C}$ \\
Permeability & $7.5 \times 10^{-12} \mathrm{k} / \mathrm{m}^{2}$ & Steam chamber angle & $45^{\circ}$ \\
Reservoir thickness & $20 \mathrm{~m}$ & Chamber temperature & $280^{\circ} \mathrm{C}$ \\
Caprock thickness & $15 \mathrm{~m}$ & Reservoir temperature & $30^{\circ} \mathrm{C}$ \\
Well spacing & $100 \mathrm{~m}$ & Reservoir density & $2500 \mathrm{~kg} \cdot \mathrm{m}^{-3}$ \\
Horizontal well length & $350 \mathrm{~m}$ & Convective phase density & $1500 \mathrm{~kg} \cdot \mathrm{m}^{-3}$ \\
Reservoir pressure & $1.2 \mathrm{MPa}$ & Moving speed of steam & $2.5 \times 10^{-2} \mathrm{~m} / \mathrm{d}$ \\
Oil viscosity & $2.4 \times 10^{5} \mathrm{mPa} \cdot \mathrm{s}$ & Thermal diffusivity & $7.5 \times 10^{-7} \mathrm{~m}^{2} / \mathrm{s}$ \\
Water specific heat capacity & $4200 \mathrm{~J} /(\mathrm{kg} \cdot \mathrm{K})$ & Original oil saturation & 0.85 \\
Oil specific heat capacity & $1800 \mathrm{~J} /(\mathrm{kg} \cdot \mathrm{K})$ & Connate-water saturation & 0.15 \\
Thermal conductivity & $1.5 \mathrm{~W} /\left(\mathrm{m} \cdot{ }^{\circ} \mathrm{C}\right)$ & Relative permeability of bound water oil phase & 0.85 \\
Injection pressure & $1.80 \mathrm{MPa}$ & Absolute reservoir permeability & $6 \times 10^{-12}$ \\
Pressure-viscosity factor & 2 & Relative permeability of water phase under residual oil \\
Temperature-viscosity factor & 3 & & 0.03 \\
\hline
\end{tabular}

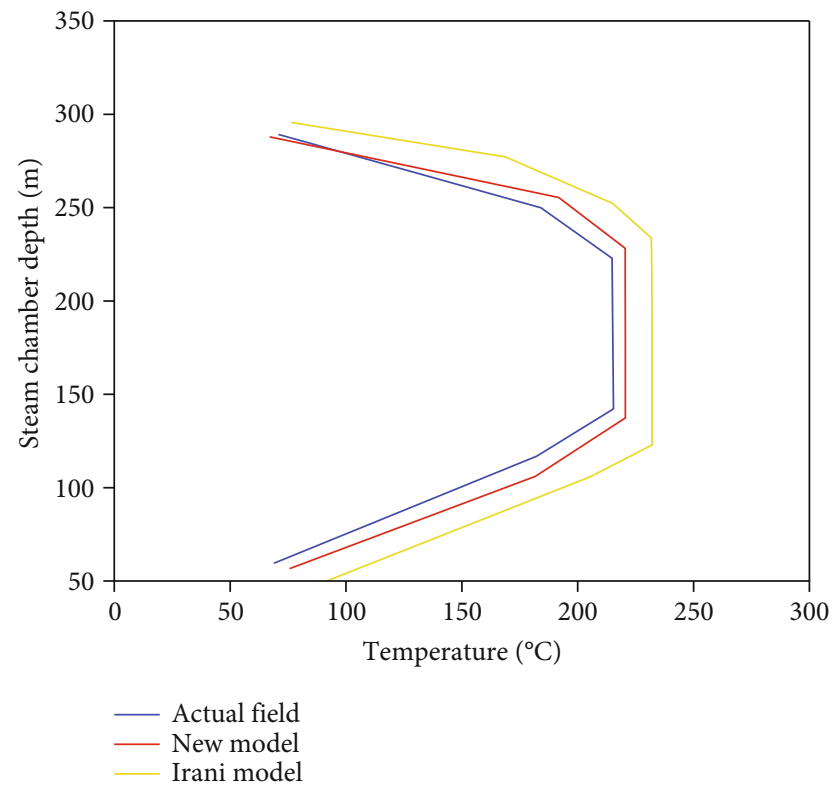

FIGURE 5: Schematic of temperature change curves of different steam chambers.

of the new model and actual mine data. In particular, in the interval where the depth of the steam chamber is 150-200 $\mathrm{m}$, the new model is closest to the actual field data, which shows the new steam cavity expansion speed model for steam-assisted gravity drainage is correct.

The edge position of the steam chamber can be calculated when the edge of the steam chamber passes through the observation well. MATLAB was used to calculate and simulate the edge position of the steam chamber at different times. Figure 6 shows that in 2018, the predicted edge of the steam chamber moved $22.51 \mathrm{~m}$ in the $X$ direction, and the steam chamber migration speed at this time was $2 \times 10^{-2} \mathrm{~m} /$ day. The edge position of the steam chamber was $22.83 \mathrm{~m}$, which was obtained via four-dimensional seismic data detection.
The two data were very consistent, verifying the accuracy of the new model established herein.

\section{Application}

4.1. Temperature Distribution at the Edge of the Steam Chamber. Although thermal convection is considered in existing heat transfer equations for the production process of steam-assisted gravity drainage, only the water phase is considered as the convection phase in the model, and this ignores the role of heavy oil in the thermal convection process. Thus, the new model deviates slightly from the actual situation. Therefore, we herein comprehensively consider the oil-water two-phase flow and the mixed relative flow velocity, establish the SAGD heat transfer model, including heat conduction and heat convection, and calculate the temperature distribution at the edge of the air cavity.

Through the establishment of this temperature distribution, when the steam chamber drain zone reaches a certain observation position, the position of the steam chamber's front edge and its temperature can be obtained in real-time to predict the width of the drain zone and the movement speed of the steam chamber [2, 23-25]. Furthermore, by incorporating the geological parameters of Well $\mathrm{Z}$ into the temperature equation at the edge of the steam chamber, a temperature distribution map of the oil drainage zone can be obtained. As shown in Figure 7, as the production time for steam-assisted gravity drainage increases, the horizontal expansion speed of the steam chamber gradually decreases, as does the temperature of the front edge of the steam chamber. The shape of the drain zone gradually flattens, but the temperature of the steam chamber remains stable. This indicates that as the production years increase, the output gradually stabilises, which is in line with the actual situation. By studying the temperature changes at the edge of the steam chamber, the temperature distribution of the front edge of the steam chamber can be quantitatively characterised, thereby providing theoretical support for actual production. 


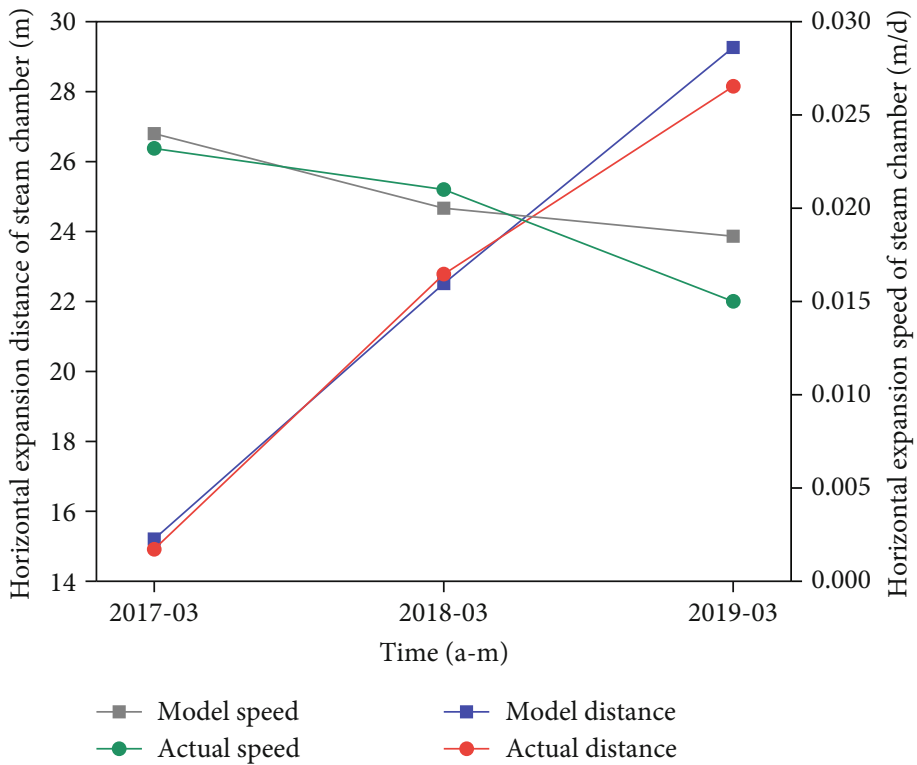

Figure 6: Schematic of the edge and velocity distribution of the steam chamber at different times.

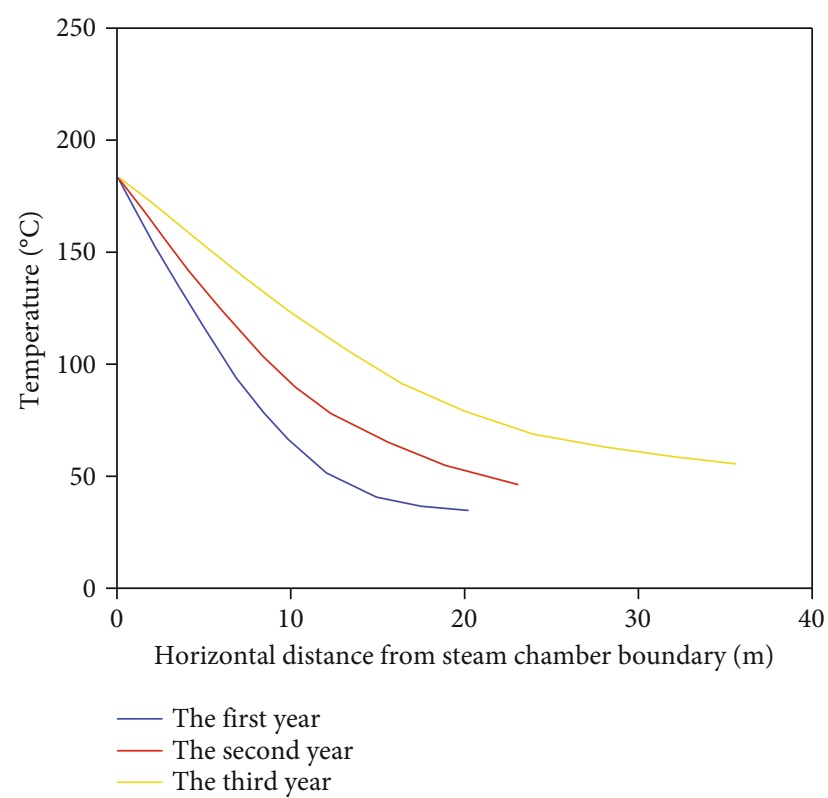

FIGURE 7: Schematic of temperature distribution at the edge of the steam chamber.

4.2. Sensitivity Analysis of Steam Chamber Expansion Speed. To help the field better understand the influencing factor of the steam chamber's horizontal expansion speed during the SAGD generation process, sensitivity analysis is performed to maintain the shape of the gas chamber and improve the recovery factor. Under the condition of measuring the position and temperature of the oil layer, in accordance with Equation (25), we can obtain the expansion speed of the steam chamber under different production times, and a sensitivity analysis of the expansion speed of the steam chamber can be carried out to analyse the influence of different influencing factors on the expansion speed of the steam chamber. The data used in the sensitivity analysis are listed in Table 2.
(1) Analysis of the influence of thermal conductivity

Figure 8 shows that the horizontal expansion speed of the steam chamber is directly proportional to thermal conductivity. The larger the thermal conductivity of the steam chamber, the faster is the horizontal expansion speed, and the larger is the moving distance [26-28]. On the contrary, when the thermal conductivity is small, the heat transfer of the steam will slow. Although thermal convection will still occur when it is small, the time the heavy oil in the reservoir has to be affected by the steam will be considerably reduced, which directly leads to the horizontal expansion speed of the steam cavity. If it slows down, the horizontal extension distance will also slow; this will eventually lead to a decrease in the SAGD oil displacement effect and a decrease in oil recovery.

(2) Analysis of the influence of the reservoir heat capacity

Heat capacity generally refers to the specific heat capacity, i.e., the energy required for the oil phase material to increase the temperature. Under the condition of controlling other unchanged values, the heat capacity of the reservoir is increased from $1 \times 10^{6} \mathrm{~J} /\left(\mathrm{m}^{3} \cdot \mathrm{K}\right)$ to $3 \times 10^{6} \mathrm{~J} /\left(\mathrm{m}^{3} \cdot \mathrm{K}\right)$. As shown in Figure 9, as the specific heat capacity of the reservoir continued to increase, the horizontal expansion rate of the steam cavity decreased. This indicates that a larger specific heat capacity in the reservoir hinders the development of the steam cavity and reduces the SAGD and horizontal expansion speed of the steam chamber during production. This is because the higher the viscosity and density of the heavy oil, the higher is the specific heat capacity of the crude oil [29-33]. However, more energy is consumed in the process of reducing the viscosity of heavy oil. In the case of limited thermal steam energy, the greater the specific heat capacity of the heavy oil, the lower is the transmission efficiency, and the lower is the horizontal expansion speed of 
TABLE 2: Sensitivity analysis parameter table.

\begin{tabular}{lc}
\hline Item & Value \\
\hline Reservoir temperature & $30^{\circ} \mathrm{C}$ \\
Thermal diffusivity & $7.5 \times 10^{-7} \mathrm{~m}^{2} / \mathrm{s}$ \\
Oil specific heat capacity & $1800 \mathrm{~J} /(\mathrm{kg} \cdot \mathrm{K})$ \\
Reservoir density & $2500 \mathrm{~kg} \cdot \mathrm{m}^{-3}$ \\
Convective phase density & $1500 \mathrm{~kg} \cdot \mathrm{m}^{-3}$ \\
Steam chamber angle & $45^{\circ}$ \\
Pressure-viscosity factor & 2 \\
Temperature-viscosity factor & 3 \\
\hline
\end{tabular}

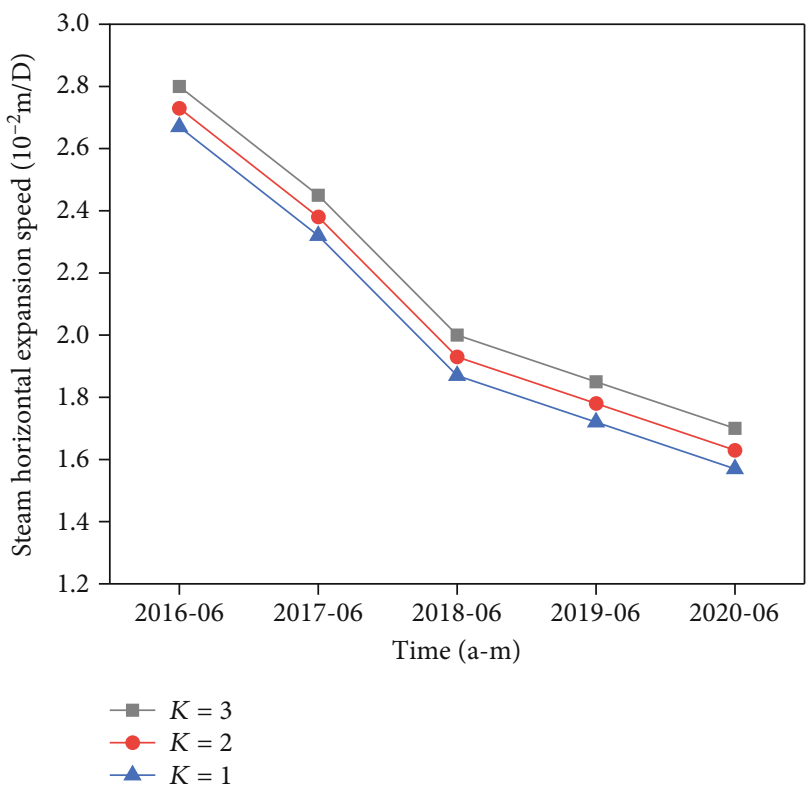

FIgURe 8: Schematic of the lateral expansion speed of the steam chamber under different thermal conductivities.

the steam chamber, which is not conducive to the development of the steam chamber and results in a decrease in oil recovery.

(3) Analysis of influence of convective liquid heat capacity

Although several studies have considered the influence of thermal convection, there are deviations in the understanding of the components of the convection fluid. This indicates that the research results are inaccurate and cannot accurately describe the thermal convection during the development and expansion of the steam cavity. In this study, the components of the convective liquid were regarded as the mixed phase of the water and oil phases. Therefore, to analyse its influence on the horizontal expansion speed of the steam chamber, the control variable method was used to explore the influence of the mixed-phase convective liquid on the horizontal expansion speed.

Figure 10 shows that as the specific heat capacity of the convective liquid continues to increase, so does the steam

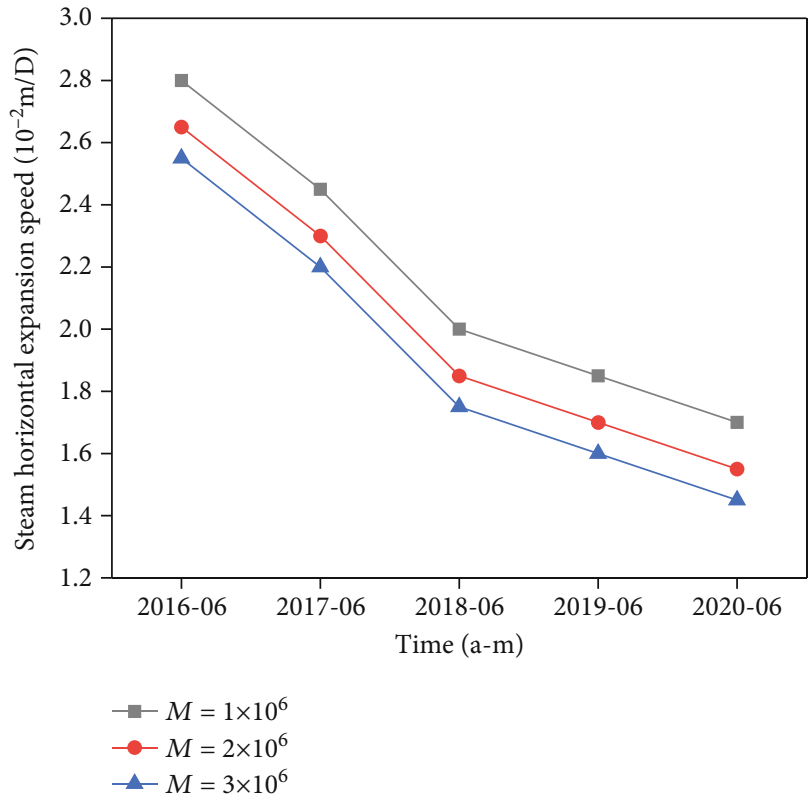

FIGURE 9: Schematic of the lateral expansion speed of steam cavity under different reservoir heat capacities.

chamber's horizontal expansion speed and that the two are shown to be in a proportional relation. As the convection liquid is composed of two miscible phases-a water phase and an oil phase-when the specific heat capacity of the convection liquid increases, the water phase in the miscible phase accounts for a larger proportion. In addition, the speed with which the steam spreads will increase, while the steam's energy from the heat will slowly decrease. Therefore, the chamber's horizontal expansion speed is also at a maximum.

When the specific heat capacity of the convective liquid decreases, the proportion of the oil phase increases, the crude oil in the area affected by the thermal energy of the steam thickens, the viscosity of the convective liquid increases, and the chamber's horizontal expansion speed decreases. This conclusion allows for a better understanding of the influence of the specific heat capacity of the convection liquid on the horizontal expansion speed of the steam chamber during the steam diffusion stage, thus, providing a theoretical basis for actual field development.

4.3. Production Calculation Based on Expansion Speed of Steam Chamber. During the SAGD production process, there are often differences in the interface speed of the steam chamber at different times owing to the different production systems. However, most existing production studies are based on Butler's traditional equation that ignores the heat convection as well as the influence of the steam chamber's varying expansion speeds at different times on the output. Therefore, according to the existing production equations $[1,34]$, we obtain

$$
q=\frac{M_{\mathrm{p}} K g L \sin \theta}{m \mu_{s} U_{\xi} \rho_{r} c_{p r}},
$$




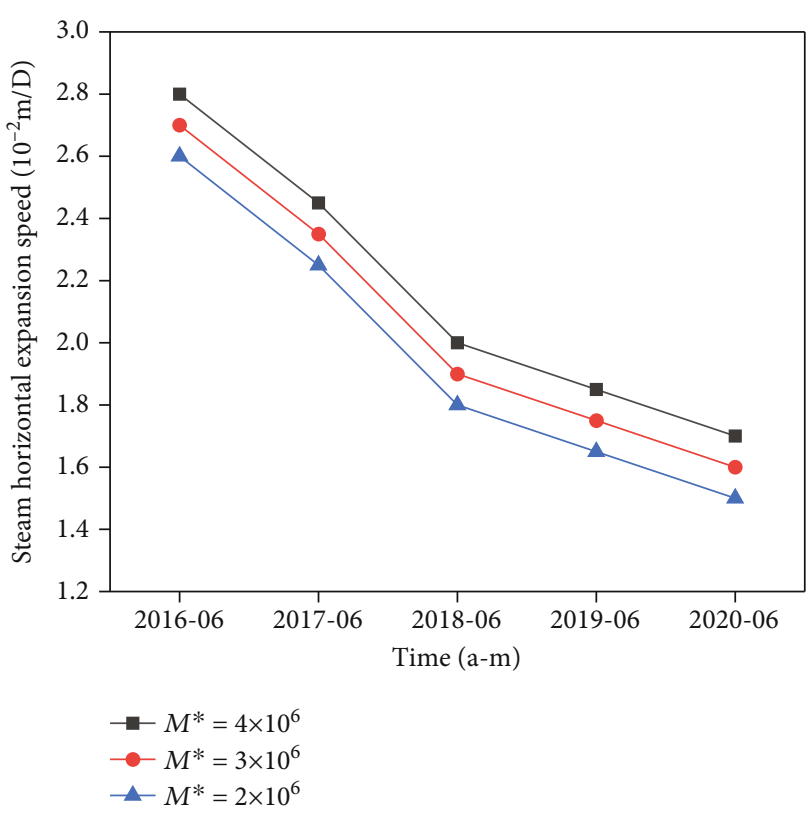

FIGURE 10: Schematic of the lateral expansion speed of the steam chamber under different convective liquid heat capacities.

TABLE 3: Basic parameter table for yield calculation.

\begin{tabular}{lc}
\hline Item & Value \\
\hline Viscosity-temperature constant & 2 \\
Acceleration of gravity & $9.8 \mathrm{~m}^{2} / \mathrm{s}$ \\
Thermal diffusivity & $9.5 \times 10^{-2} \mathrm{~m}^{2} / \mathrm{d}$ \\
Oil kinematic viscosity & $5 \times 10^{-6} \mathrm{~m}^{2} / \mathrm{s}$ \\
Effective permeability of the oil phase & $0.45 \times 10^{-12} \mathrm{~m}^{2}$ \\
Horizontal section length & $350 \mathrm{~m}$ \\
\hline
\end{tabular}

where $M_{p}$ is the effective permeability of the oil phase and $L$ is the length of the horizontal section.

On incorporating Equation (25) into Equation (26), we get

$$
q=\frac{M_{\mathrm{p}} g \alpha L}{m \mu_{s} U_{X}} .
$$

The above equation becomes a production equation (oil production) that considers the horizontal expansion speed of the steam chamber. This equation can be used to perform actual field fitting and production predictions to guide field development.

According to the expansion speed of the steam chamber across different time periods, the SAGD production at different times can be obtained. To facilitate the popularisation and application of this method, the actual production at different time nodes is used to fit Equation (27), and the basic parameter list is shown in Table 3. By inputting the data from the table into the production model, the average daily oil production in the model during the third year is observed to be $59.32 \mathrm{~m}^{3} /$ day, and the actual average daily production from

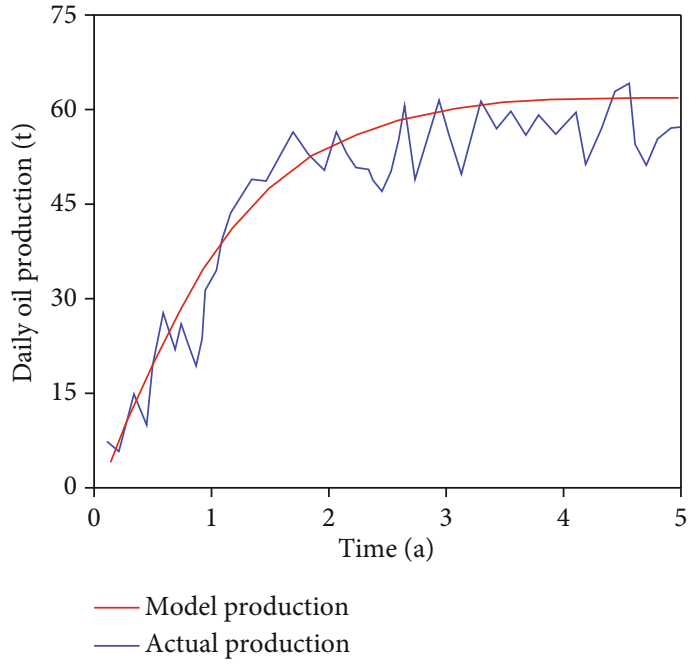

FIgURE 11: Comparison chart of the actual production and calculated production.

Well $\mathrm{Z}$ is $55.67 \mathrm{~m}^{3} /$ day, when ignoring the effect that heat loss has. The following two data points are close, verifying that the model can meet production forecast requirements. In addition, the steam chamber's varying expansion speeds when at different production times is brought into the output equation, and once the curve is smoothed, a comparison chart showing the actual output and model calculated output is obtained (as shown in Figure 11).

Through the actual output and the calculated output comparison chart, the calculated output and the actual output have the same curve trend, but the model's output enters the stable production period earlier than the actual output, and the cumulative oil production is slightly higher than in the actual field. This is because the calculated production model ignores the heat lost during movement in the steam chamber and simplifies the steam chamber into an inverted triangle. In addition, owing to other influencing factors such as operations in the actual field, the calculated output will be slightly higher than the actual output, and thus it enters the stable production period sooner.

\section{Conclusions}

The development and expansion of the steam cavity are decisive factors for steam-assisted gravity drainage to ensure its recovery factor. We herein established the steam cavity's heat transfer and expansion speed models by considering various influencing factors and then validated the model. The study of the mechanism model yielded the following conclusions.

(1) During the horizontal expansion stage of the steam cavity interface toward the reservoir, heat conduction and thermal convection occur simultaneously, and heat flows perpendicular to the steam cavity's interface under the action of the pressure difference. The convective liquid here is a combination of the water and oil phases, with the oil phase being an important part of the convective liquid 
(2) According to the actual well field, the observation well data obtained, and the analysis of the steam chamber expansion speed model, the steam chamber expansion speed was the largest in the early stages of SAGD production. With the increase in production time, the expansion speed of the steam chamber will decrease, and at this time, it needs to be changed. This can be achieved by changing the production system or changing the production method to add energy to the injection well, thereby maintaining high efficiency and stable production

(3) After studying the sensitivity of the steam chamber expansion speed model, under the condition of other factors being constant, the greater the thermal conductivity of the reservoir, the faster is the steam chamber expansion speed. In this case, the heat capacity of the oil reservoir will require more heat energy to reduce viscosity, and the expansion speed of the steam chamber will also decrease. This is because as the convective liquid is miscible, the greater the heat capacity, the greater is the water phase ratio, indicating that the convective liquid will have low viscosity and the steam chamber will expand quickly

(4) The established SAGD heat transfer model was used to derive the temperature distribution function at the edge of the steam chamber. This predicts the expansion shape of the steam chamber and the edge temperature change and provides a theoretical basis for the subsequent dynamic control of production. Based on Butler's classic production equation, a production equation that considers the expansion speed of the steam chamber is established. Finally, by looking at the change in expansion speeds of the steam chamber (due to the working system) at different time periods, oil production can be accurately calculated at different times. This will help advance field development

\section{Nomenclature}

K: $\quad$ Reservoir thermal conductivity, $\mathrm{W} / \mathrm{m} \cdot{ }^{\circ} \mathrm{C}$

$\alpha: \quad$ Thermal diffusivity, $\mathrm{m}^{2} / \mathrm{s}$

$\rho_{c}$ : $\quad$ Convective phase density, $\mathrm{kg} \cdot \mathrm{m}^{-3}$

$\rho_{r}: \quad$ Reservoir density, $\mathrm{kg} \cdot \mathrm{m}^{-3}$

$c_{p c}$ : Specific heat capacity of the convective liquid, $\mathrm{J} /(\mathrm{kg} \cdot \mathrm{K})$

$c_{p r}: \quad$ Specific heat capacity of the reservoir, $\mathrm{J} /(\mathrm{kg} \cdot \mathrm{K})$

$\mu_{s}$ : Oil phase viscosity when at the injected steam temperature, $\mathrm{mPa} \cdot \mathrm{s}$

$\mu_{0}: \quad$ Oil viscosity, mPa.s

T: $\quad$ Temperature at a certain point on the edge of the steam chamber, ${ }^{\circ} \mathrm{C}$

$T_{r}: \quad$ Original reservoir temperature, ${ }^{\circ} \mathrm{C}$

$T_{s}$ : Temperature of the injected steam, ${ }^{\circ} \mathrm{C}$

$m$ : Temperature-viscosity factor, dimensionless

n: $\quad$ Pressure-viscosity factor, dimensionless

$P$ : $\quad$ Pressure at a certain point on the edge of the steam chamber, $\mathrm{MPa}$
$P_{r}: \quad$ Original reservoir pressure, $\mathrm{MPa}$

$P_{s}: \quad$ Steam injection pressure, $\mathrm{MPa}$

$k_{r o}$ : Relative permeability of the oil phase, dimensionless

$k_{\text {rocw }}$ : Relative permeability of the oil phase when under an irreducible water saturation, dimensionless

$k_{r w}$ : Relative permeability of the water phase, dimensionless

$k_{\text {rwro }}$ : Relative permeability of the water phase under the residual oil saturation, dimensionless

$S_{i o}: \quad$ Initial oil saturation, dimensionless

$S_{\text {or }}$ : Residual oil saturation, dimensionless

$S_{O D}$ : Normalized oil saturation, dimensionless

$S_{w c}$ : Connate-water saturation, dimensionless

$a: \quad$ Corey coefficient, which sets the curvature of the oil relative permeability curve, dimensionless

$b$ : Corey coefficient, which sets the curvature of the water relative permeability curve, dimensionless

$\theta$ : Angle of steam chamber and horizontal line,

$M_{p}: \quad$ Effective permeability of the oil phase, $\mathrm{m}^{2}$

$L$ : $\quad$ Length of the horizontal section, $\mathrm{m}$.

\section{Data Availability}

No data were used to support this study.

\section{Conflicts of Interest}

The authors declare that there is no conflict of interest regarding the publication of this paper.

\section{Acknowledgments}

This article is especially grateful to Professor Wen-Dong Wang from China University of Petroleum (East China) for his great support and help in writing. The project was funded by Sinopec Shengli Oilfield Exploration and Development Research Institute, and the funded subject was "Research on the Expansion Law and Dynamic Control Technology of Heavy Oil Steam Drive Cavity".

\section{References}

[1] R. M. Butler, "A new approach to the modelling of steamassisted gravity drainage," Journal of Canadian Petroleum Technology, vol. 24, no. 3, pp. 42-51, 1985.

[2] R. M. Butler, G. S. McNab, and H. Y. Lo, "Theoretical studies on the gravity drainage of heavy oil during in-situ steam heating," The Canadian journal of chemical engineering, vol. 59, no. 4, pp. 455-460, 1981.

[3] M. Nukhaev, V. P. Pimenov, A. Shandrygin, and V. V. Tertychnyi, "A new analytical model for the SAGD production phase," in SPE annual technical conference and exhibition, San Antonio, TX, USA, 2006.

[4] J. Sharma and I. D. Gates, "Multiphase flow at the edge of a steam chamber," Canadian Journal of Chemical Engineering, vol. 88, no. 3, pp. 312-321, 2010.

[5] M. Irani and S. Ghannadi, "Understanding the heat-transfer mechanism in the steam-assisted-gravity-drainage (SAGD) process and comparing the conduction and convection flux 
in bitumen reservoirs," SPE Journal, vol. 18, no. 1, pp. 134145, 2013.

[6] L. Qing and X. C. Zhang, "A new analysis on the convective heat transfer at the edge of the SAGD chamber," in SPE Annual Technical Conference and Exhibition, Houston, TX, USA, 2015.

[7] R. Yang, J. Zhang, L. Yang, H. Chen, and S. Tang, "Performance and calculation method of steam chamber overcoming high water saturation intervals during SAGD process," in Paper IPTC-18747-MS presented at the International Petroleum Technology Conference, Bangkok, Thailand, 2016.

[8] J. Fan and X. F. Li, "Research on the heat transfer model of the front edge of the steam cavity for steam-assisted gravity drainage," Science Technology and Engineering, vol. 16, no. 3, pp. 42-47, 2016.

[9] I. D. Gates, J. Kenny, I. L. Hernandez-Hdez, and G. L. Bunio, "Steam injection strategy and energetics of steam-assisted gravity drainage," SPE Reservoir Evaluation and Engineering, vol. 10, no. 1, pp. 19-34, 2007.

[10] D. R. Gotawala and I. D. Gates, "Stability of the edge of a SAGD steam chamber in a bitumen reservoir," Chemical Engineering Science, vol. 66, no. 8, pp. 1802-1809, 2011.

[11] Z. X. Zhang, H. Q. Liu, X. H. Dong, P. Qi, H. L. Jiang, and Y. Yang, "Research on a new model of steam-assisted gravity drainage," Energy and Environmental Protection, vol. 39, no. 11, pp. 9-13, 2017, 19.

[12] Y. Zhou, T. Lu, S. Y. Wu, L. X. Shi, X. Du, and J. L. Wang, "Calculation model and application of steam cavity expansion velocity of dual horizontal well steam assisted gravity drainage," Petroleum Exploration and Development, vol. 46, no. 2, pp. 334-341, 2019.

[13] Z. Zeinab, S. M. Razavi, and S. M. F. Ali, "Analytical model of steam-assisted gravity drainage (SAGD) process in relation to constant injection rate," Fuel, vol. 265, p. 116772, 2020.

[14] X. X. Liu, Y. W. Jiang, Y. B. Wu, and J. Wang, "Mathematical model and index prediction of constant temperature electric preheating with steam assisted gravity drainage for dual horizontal wells," Petroleum Exploration and Development, vol. 45, no. 5, pp. 839-846, 2018.

[15] B. L. Liu, "Study on SAGD physical simulation of thickened oil in thin bed," Chemical Engineer, vol. 179, no. 8, pp. 16-20, 2010.

[16] C. F. Wang, G. H. Wu, T. Wei, and Y. H. Sun, "Physical simulation experiment of nitrogen gas and dissolve solvent aided SAGD for thin formation and extra-super heavy oil reservoir," Petroleum Geology and Recovery Efficiency, vol. 24, no. 1, pp. 81-85, 2017.

[17] R. M. Butler and D. J. Stephens, "The gravity drainage of steam-heated heavy oil to parallel horizontal wells (in English) PETSOC-81-02-07," Journal of Canadian Petroleum Technology, vol. 20, no. 2, pp. 90-96, 1981.

[18] M. C. Mazdairani, "Discussion on the effects of temperature on thermal properties in the steam-assisted-gravity-drainage (SAGD) process," Part 1: Thermal conductivity. SPE 170064MS, 2014.

[19] W. Shaolei, C. Linsong, H. Wenjun, H. Shijun, and L. Shuai, "Prediction for steam chamber development and production performance in SAGD process," Journal of Natural Gas Science \& Engineering, vol. 19, no. 7, pp. 303-310, 2014.

[20] D. S. Ma, J. Guo, and C. Zan, "Physical simulation of steamassisted gravity drainage to improve the uniformity of steam cavity development," Petroleum Exploration and Development, vol. 40, no. 2, pp. 188-193, 2013.

[21] X. Chen, Y. L. Jia, L. X. Sang, and M. Qing, "A new method to determine the development speed and range of the steam cavity front of steam gravity recovery (SAGD)," Reservoir Evaluation and Development, vol. 6, no. 1, pp. 36-39, 2016.

[22] J. Tian, H. Q. Liu, Z. X. Pang, W. Zhao, Z. N. Gao, and S. X. Bing, "SAGD three-dimensional physical simulation experiment of double-horizontal well in high pressure environment," Acta Petrolei Sinica, vol. 38, no. 4, pp. 453-460, 2017.

[23] S. Chen, B. Ding, L. Gong, Z. Huang, B. Yu, and S. Sun, "Comparison of multi-field coupling numerical simulation in hot dry rock thermal exploitation of enhanced geothermal systems," Advances in Geo-Energy Research, vol. 3, no. 4, pp. 396-409, 2019.

[24] S. Huang, H. Xiong, and M. A. Kuiqian, "SAGD production capacity prediction model considering non-uniform steam absorption along the way," Journal of China University of Petroleum (Edition of Natural Science), vol. 41, no. 4, pp. 107-115, 2017.

[25] X. Sun, B. Xu, G. Qian, and B. Li, “The application of geomechanical SAGD dilation startup in a Xinjiang oil field heavyoil reservoir," Journal of Petroleum Science and Engineering, vol. 196, pp. 7-75, 2021.

[26] K. Sasaki, A. Satoshi, N. Yazawa, and F. Kaneko, "Microscopic visualization with high resolution optical-fiber scope at steam chamber interface on initial stage of SAGD process," in Presented at the SPE/DOE Improved Oil Recovery Symposium, Society of Petroleum Engineers, 2002.

[27] F. Xu, Q. Chen, M. Ma, Y. Wang, F. Yu, and J. Li, “Displacement mechanism of polymeric surfactant in chemical cold flooding for heavy oil based on microscopic visualization experiments," Advances in Geo-Energy Research, vol. 4, no. 1, pp. 77-85, 2020.

[28] H. Dehghanpour, M. Murtaza, and Z. He, "Modeling threephase flow during steam chamber rise-impact of water drainage on oil production rate," in Presented at the SPE Heavy Oil Conference-Canada, Calgary, Alberta, Canada, 2013.

[29] C. Harden, "Discount rate development in oil and gas valuation," in SPE hydrocarbon economics and evaluation symposium, Houston, Texas, USA, 2014.

[30] A. Honarvar, J. Rozhon, and D. Millington, Economic Impact of New Oil Sands Projects in Alberta (2010-2015), 2011, ISBN 1-896091-99-7.

[31] J. Vogel, "Simplified heat calculations for steamfloods," Journal of petroleum technology, vol. 36, no. 7, 1984.

[32] Y. Ito, T. Hirata, and M. Ichikawa, "The growth of the steam chamber during the early period of the UTF phase B and hangingstone phase I projects," Journal of Canadian Petroleum Technology, vol. 40, no. 9, 2001.

[33] J. J. Ijeje, Q. Gan, and J. Cai, "Influence of permeability anisotropy on heat transfer and permeability evolution in geothermal reservoir," Advances in Geo-Energy Research, vol. 3, no. 1, pp. 43-51, 2019.

[34] F. L. Zhang, L. P. Zhang, J. G. Bao, and H. Zhang, “The steamassisted heavy-duty oil drainage technology is in super thick application in oil development," Special Oil and Gas Reservoir, vol. 14, no. 2, pp. 70-72, 2007. 